\title{
A THREE YEAR CLINICAL EVALUATION OF DALACIN IN THE TREATMENT OF LEPROMATOUS LEPROSY
}

\author{
by Dr. J. A. DrFisbaCh, A.B., M.D.
}

Medical Missionary of the Sudan Interior Mission; Medical Superintendent, Kano Leprosarium, Nigeria

and

Dr. R. G. Cochrane, M.D., F.R.C.P., D.T.M. \& H.

Technical Medical Adviser, American Leprosy Mission, Inc. Adviser in Lepros!', Ministry' of Health, London

The Research Laboratories of the Upjohn Company, Kalamazoo, Michigan, U.S.A., have isolated a new antimicrobic complex produced under conditions of submerged fermentation by Streptomy'ces spectahilis, an Actinomycete isolated from a sample of soil from Dallas, Texas, U.S.A. The laboratory designation of Antibiotic 10 la bears the generic name Streptovaricin and has subsequently been marketed under the trade name of Dalacin.

Streptovaricin has been demonstrated to have a high degree of activity against $M$ vcohacterium tuherculosis, both in vitro and in vivo, and it has also proved active in in vitro against a number of grampositive, gram-negative and saprophytic acid-fast bacteria.

Under the same conditions of in vitro tests, Streptovaricin proved approximately 10 times as active as Streptomycin, 100 times as active as para-amino-salicylic acid, and half as active as isonzaiid.

Streptovaricin proved highly effective in treating mice infected with $M$. tuherculosis (c37Rv). When the microbic enumeration technique was employed. Streptovaricin and isoniazid given together produced an anti-tuberculosis effect that was considerably greater than was achieved with either drug alone. ${ }^{1,2,3,4}$

Streptovaricin resulted in regression and healing of tuberculosis lesions in guinea pigs infected with tubercle bacilli resistant to Streptomycin and to P.A.S. ${ }^{6}$ It was also shown to exert a suppressive action against murine leprosy in mice.

Studies on the biological distribution of Streptovaricin revealed that it was well absorbed from all parts of the digestive tract except possibly the stomach.'

In view of the encouraging preliminary laboratory investigation, the clinical evaluation of Streptovaricin in human mycobacterial infection was undertaken. There have been rather extensive studies of the therapeutic effect of Streptovaricin in human pulmonary tuberculosis. For the most part, these have all been discouraging. Nathan makes the following observations: ${ }^{\text {x }}$ 
1. Streptovaricin does not delay the emergence of tubercle bacilli resistant to Isoniazid.

2. Streptovaricin ( 3 gms./day orally) along with Isoniazid provides no more in therapeutic efficiency than might be achieved in Isoniazid alone.

3. Toxicity due to Streptovaricin in the dosage levels used was severe enough to warrant withdrawal of the drug in 1/5 of the cases. Nausea, vomiting and diarrhoea were the most commonly encountered symptoms.

Similar conclusions have been reached by other investigators."., 111 In another study of the emergence of bacillary resistance to Streptovaricin in 10 patients it was shown that varying degrees of resistance developed in all cases. ${ }^{11}$

The purpose of this paper is to report the findings of a three year clinical evaluation of the therapeutic effect of Streptovaricin in a small series of cases of Lepromatous leprosy treated at the Kano Leprosarium of the Sudan Interior Mission in Northern Nigeria.

\section{Method}

The patients chosen for this study were all far advanced cases of lepromatous leprosy. With the exception of the first case all were previously untreated. Preliminary studies included C.B.C., urine, stool, sedimentation rate, skin smear, biopsy and photograph. The C.B.C., urine, stool and skin smear were repeated monthly during the course of this study, and repeat biopsies and photographs were taken approximately every 6 months.

\section{Procedure}

Streptovaricin was supplied in $200 \mathrm{mgm}$. capsules. The drug was given daily, with the exception of Sunday, up to 3 gms. at which level it was maintained. The study was instituted in January, 1957.

\section{Case Reports}

1. SA'A Kankasa. No. 2316. 20-year-old Fulani female.

This patient was first admitted in 1949, as a 12-year-old girl. At that time she had 2 years of Diasone treatment and then left against medical advice.

She was re-admitted in January, 1957, having had no treatment in the intervening more than 6 years. She was in very poor condition with marked progression of the disease, being a far advanced case of lepromatous leprosy. There were marked mucosal lesions, nasal septal ulceration, perforation and collapse of the nasal arch. There were buccal and laryngeal nodules, and diffuse infiltrative lesions with ulceration. There was widespread heavy diffuse infiltration of the whole body, the heaviest being on the face.

She was started on Streptovaricin in February, 1957. The drug was very well tolerated. At no time were any toxic manifestations noted. She did experience two very mild ENL reactions at the 6 th and 15 th months. Neither of these reactions was severe enough to warrant interruption of the treatment.

It was noted that there was a tendency to a chronic dermamycosis during the course of this sutdy. A total of 34 months' treatment have been completed at the time of this report. Total dose: 2128,6 grams. 
We noted that there was a definite clinical improvement as seen in the moderate resolution of the heavy diffuse infiltrative lesions. There remained, however, definite clinical infiltrative lesions, particularly of the extremities. The nasal septal mucosal ulceration persisted. The buccal and laryngeal involvement has shown some improvement. The bacteriological index (Ridley) (12) came from a high of 5.6 in April, 1957, to a low of 2.8 at the time of this report.

Histopathological Reports on biopsy material sent for examination: 1st Biopsy (26/1/57), 525 (Lab. No. 2495)

H. E. Section: There is a massive infiltration occupying the whole of the dermis up to the epidermis, but leaving a narrow quite clear sub-epidermal zone. The infiltrate consists almost entirely of macrophages, many of which have undergone commencing foamy cell change. Amidst the infiltration there are round cells and a significant number of plasma cells. The nerves, however, are quite unrecognisable, owing to the intensity of the granulomatous tissue. This may indicate, however, that the patient may have passed through the dimorphous phase.

F. F. STAIN: Very numerous bacilli seen all through the granulomatous area showing no morphological change, and there are no characteristic globi.

DIAGinosis: A very active, moderately advanced lepromatous case.

2nd Biopsy (19/2/58), 555 (Lab. No. 3014)

H. E. Section: The whole of the corium is occupied by a gross infiltration not extending up to the epidermis, but leaving a relatively clear sub-epidermal zone. The infiltrate is seen to be chiefly round cells in the background of foamy cell change. In addition there are fairly numerous plasma cells. In this gross infiltration nerves are almost impossible to recognise.

F. F. Stain: Large numbers of acid-fast bacilli seen throughout the section, showing some morphological change.

DiAGNosis: This is a moderately advanced lepromatous case showing considerable activity, and is probably under the influence of therapy.

3rd Biopsy (22/1/59), 572 (Lab. No. 3357)

H. E. Section: There is a moderately gross infiltration underneath the epidermis leaving a broad free sub-epidermal zone. The infiltrate is a more or less continuous mass going down to, but not extending deep into the subcutaneous fatty tissue. The infiltrating mass consists almost entirely of macrophages which have undergone gross foamy cell change. In between the foamy cells there is some round-celled infiltration, but this is not significant. Plasma cells are easily recognisable and show some increase. Nerves do not seem to have been included in the section, except for one which is distinctly recognisable.

F. F. Stain: Numerous acid-fast bacilli showing marked morphological change. One nerve was recognised in the longitudinal section with proliferation of Schwann cells, some of which contain a number of bacilli.

DiAGiNOSIS: Moderately advanced active leproma, not in reaction, and with some evidence of being under the influence of therapy.

4th Biopsy (26/11/59), 576 (Lab. No. 3741)

H. E. Section: The whole of the superficial part of the corium underneath the epidermis is occupied by a continuous sheet of foamy cell change. The infiltration does not go up to the epidermis and leaves a relatively free, broad sub-epidermal zone. The infiltrate consists almost entirely of foamy cells. Interspersed between the foamy cells are round cells and there seems to be quite an increase in plasma cells. An occasional nerve is seen, recognised chiefly by the fact that the histiocytes have the shape of Schwann cells. Otherwise, nerves are unrecognisable.

F. F. Stain: Numerous acid-fast bacilli seen throughout the section showing little or no morphological change.

DiaGnosis: Moderately advanced lepromatous case, showing considerable activity, but not in reaction.

\section{Conclusions}

There has been very definite clinical and bacteriological improvement, but we feel it is slightly less than what we could have expected on Sulphetrone; there is no corresponding histological evidence 
indicating any improvement, in lact the last biopsy from this case showed definite deterioration in the patient's condition.

2. Yahaya Zakara. No. 4612. 17-year-old Fulani male.

This patient was first admitted in December 1956. He was a well advanced case of lepromatous leprosy. There were nodular'and diffuse infiltrative lesions, widespread, but heaviest on face and thighs. Some of the nodules had become necrotic with superficial ulceration.

There were advanced mucosal lesions, nasal septal ulceration, perforation and early collapse of the nasal arch. There were labial, buccal and laryngeal mucosal infiltrations with labial ulceration.

$\mathrm{He}$ had had no previous treatment. Treatment with Streptovaricin was started in January, 1957. The drug was well tolerated. At no time was any toxic manifestations noted. He did experience a number of mild ENL reactions.

At the 11 th, $17 \mathrm{th}, 28 \mathrm{th}$ and $32 \mathrm{nd}$ months there were mild ENL reactions, at which times the dose was reduced for a short period, but with no interruption of treatment. At the 13 th and 20 th months the ENL reactions were moderate in severity and short rest periods were given.

A total of 35 months of treatment has been completed at the time of this report. Total dose: 1214.8 grams.

We note at the time of this report that there has been definite clinical improvement. There has been moderate resolution of the nodular and diffuse infiltrative lesions. He still shows, nonetheless, moderate cutaneous and subcutaneous infiltrations, particularly of the lateral aspect of the thighs.

The nasal mucosal lesions persist with ulceration and progress in the degree of collapse of the nasal arch. There has been moderate improvement of the labial, buccal and laryngeal lesions. The bacteriological index went from a high of 5.9 at onset of treatment to a low of 3.5 at the termination of the study.

Histopathological Reports on biopsy material sent for examination:

Ist Biopsy (21/12/56), 490 (Lab. No. 2478)

H. E. Section: This shows a massive infiltration throughout the corium leaving a relatively clear sub-epidermal zone; this is somewhat vascular. The granoloma consists almost entirely of macrophages, the majority of which show foamy cell change. There is also considerable round cell infiltration and some increase in plasma cells. The nerves are very interesting; there is a very great deal of proliferation of the perineurium seen as the characteristic onion-peel appearance which is so typical of lepromatous leprosy, and in some nerves this proliferation of the perineurium results in a general constriction of the nerve tissue. The cellular invasion is mostly around the nerve rather than in the nerve, although there is some increase of the cells of Schwann.

F. F. Stain: Very numerous acid-fast bacilli seen throughout the granulomatous infiltrate and in the nerve.

DiagNOSIS: Moderately advanced lepromatous case.

2nd Biopsy (19/2/58), 548 (Lab. No. 3007)

H. E. Section: About $80 \%$ of the corium is occupied by a massive infiltration consisting of numerous foamy cells. The infiltrate does not go up to the epidermis, but leaves a relatively clear sub-epidermal zone. In the midst of the foamy cells there is a considerable round-celled infiltration with moderately numerous plasma cells. A number of nerves were seen in which there was proliferation of the perineurium and some increase of the Schwann cells. One nerve was difficult to recognise, but I think there was an increase in the cellular infiltrate consisting chiefly of Schwann cells and some roundcelled infiltration.

F. F. Stain: Very numerous acid-fast bacilli seen throughout the section showing no morphological change.

DiAgNOSIS: This is a moderately advanced lepromatous case, with indications of considerable activity. There is a little evidence that it is under the influence of therapy.

3rd Biopsy (22/1/59), 571 (Lab. No. 3356)

H. E. Section: There is a diffuse infiltration scattered throughout the dermis leaving a broad, clear sub-epidermal zone. The infiltrate is seen in masses chiefly associated with the appendages of the skin, particularly the hair follicles and the sebaceous glands. The biopsy has probably been taken from the face. The infiltration cannot be said to be focalised. The infiltrating cells 
are chicfly large histiocytes (macrophages) all of which have undergone gross foamy-cell change. In one area immediately underneath the epidermis there is what appears to be an epitheloid cell focus; macrophages look like epithelioid cells and are associated with marked round celled infiltration. On closer examination some of the epithelioid cells appear to have undergone foamy cell change, but there are a number of macrophages which could be described as epithelioid cells. The section is rich in nerves which are completely uninvaded.

F. F. Stain: Very numerous acid-fast bacilli scattered throughout the dermis and in nerves showing some morphological change.

Diagnosis: An active, moderately advanced lepromatous case. There is some evidence that there may still be some dimorphous features clinically.

4th Biopsy (20/11/59), 577 (Lab. No. 3742)

H. E. Section: This shows a moderate infiltration scattered throughout the dermis leaving a fairly broad sub-epidermal zone. The infiltrate is not continuous but is mostly around the skin appendages, the sweat glands, the sebaceous cysts and the neuro-vascular strands. The infiltrate consists almost entirely of well developed foamy cells. There are collections of foamy cells; here and there, between the foamy cells there are also some plasma cells. Several nerves are very clearly seen and cut longitudinally showing no invasion whatever.

F. F. Stain: Moderate numbers of acid-fast bacilli seen scattered through every field of the microscope. They show some, but not marked morphological change.

Diagnosis: This is a moderately early lepromatous case showing some activity, but not in reaction.

\section{Conclusions}

Although there was definite clinical and bacteriological improvement, we feel that it was no more, if as much, as we could have expected on Sulphone. This opinion is supported by the fact that from a study of the histopathological sections there is no indication of any definite improvement in the patient's condition.

3. Amina Dabi. No. 4629. 30-year-old Fulani female.

This patient was first admitted in January, 1957. At that time she was a far advanced case of lepromatous leprosy. There were widespread heavy nodular and diffuse infiltrative lesions. Face, arms, and trunk posteriorly were the heaviest areas affected. There was marked nasal septal mucosal ulceration. Marked labial and moderate buccal and laryngeal mucosal infiltration.

She had had no previous treatment. Streptovaricin was started in February, 1957. The drug was very well tolerated. At no time were any toxic manifestations noted. She did show two mild ENL reactions. At the 17th month, one week rest. At the 30th month, the dose was reduced but treatment was not interrupted.

A total of 34 months' treatment has been completed. Total dose: 2426,2 grams.

At this time we can make the following observations. There has been very definite clinical improvement as seen in the resolution of the very heavy nodular and diffuse infiltrative lesions. There does remain moderate infiltrative lesions, particularly in the areas of heaviest involvement mentioned above.

The nasal septal mucosal ulceration persists with progression to the point that there is now a large septal perforation. The other mucosal lesions have shown resolution and healing.

The bacteriological index went from a high of 6.0 at the onset of treatment to a low of 4.0 at the time of reporting.

Histopathological reports on biopsy material sent for examination: Ist Biopsy (2611 12157$), 526$ (Lab. No. 2496)

H. E. Section: The whole corium is occupied by a mass of infiltrate extending up to the epidermis, but leaving a narrow, relatively free sub-epidermal zone. The infiltrate occupies the whole of the corium as a broad and continuous band. The infiltrating cells are round cells, macrophages and a fair number of plasma cells. Some of the macrophages have the appearance, but not the distribution of epithelioid cells; others show quite definite foamy 
cell degeneration. Nerves, by and large, are not recognisable, although one or two can be seen with some increase in the cellular infiltrate.

F. F. Stain: Fairly numerous bacilli seen throughout the section and all the macrophages contain bacilli. Nerves can be recognised and there is an increase in the Schwann cells, but the nerves show little evidence of infiltration. Bacilli, by and large, show themselves as acid-fast rods but there are many beaded and granular forms.

Diagnosis: Active, moderately advanced lepromatous leprosy. It is difficult to say whether the bacilli are under the influence of therapy or not; there are too many well-stained acid-fast rods to be certain of this.

2nd Biopsy (191 $\left.2_{2} 158\right), 563$ (Lab. No. 3022)

H. E. Section: There is a fairly marked and diffuse round celled infiltration scattered throughout the dermis leaving a clear sub-epidermal zone. In addition there are fairly numerous plasma cells. The lymphocytic response in this section is seen in the background of well marked foamy cell change. No nerves were actually seen in the section, except one in the Fite section in which there was no involvement.

F. F. Stain: Very numerous, very granular, rather poorly stained acid-fast bacilli.

Diagnosis: This is probably a lepromatous case resolving under therapy, passing through a phase of marked activity. There are too many bacilli in the section to suggest that it is an erythema nodosum lesion, but 1 would certainly surmise that this was a very active lesion.

3rd Biopsy (22 $\left.1_{2} 1_{2} 59\right), 570$ (Lab. No. 3355)

H. E. SECTION: There is a moderately gross infiltration throughout the dermis and under the epidermis leaving a relatively clear sub-epidermal zone. The infiltrate tends to show itself in a continuous band. There is no evidence of focalisation. The infiltrating cells consist of large histiocytes (macrophages) all of which have undergone foamy cell change. In one area there is a giant cell in the middle of the foamy cell infiltrate but there is no evidence of epithelioid cells. Curiously enough there is no nerve tissue recognisable. In addition to the gross foamy cell change there is interspersed between the foamy cells a considerable amount of round celled infiltration and I should think a definite increase in plasma cells.

F. F. STAIN : Large numbers of acid-fast bacilli showing some morphological change. In this section an occasional nerve is seen cut longitudinally, in which there is an increase in Schwann cells.

Diagnosis: Apart from the presence of one solitary giant cell I would diagnose this as a moderately advanced and active lepromatous lesion.

4ih Biopsy $\left(201_{2} 111_{2} 59\right), 578$ (Lab. No. 3743)

H. E. Section: Most of the corium is occupied by a relatively gross infiltration; this does not extend up to the epidermis and leaves a relatively free sub-epidermal zone. The infiltration in the corium is practically continuous throughout, except towards one end, where the infiltrate thins out. The infiltrating cells consist almost entirely of macrophages which have undergone gross foamy cell change. In fact, the whole infiltrate looks as if a considerable number of plasma cells and some round cells are infiltrating in-between the foamy cells.

F. F. Stain: Fairly numerous acid-fast bacilli in almost every field. Many of the acid-fast bacilli are short, stumpy rods and some appear to be somewhat granular.

DiAgNosis: Active, moderate lepromatous case showing some influence under therapy.

\section{Conclusions}

The clinical and bacteriological improvement, we feel, is comparable to that which we might have expected under sulphones, but there is no evidence that there is commensurate histological improvement.

4. Shalaibu Gurgiya. No. 4631. 30-year-old Hausa male.

This patient was first admitted in January, 1957. At that time he was a very far advanced case of lepromatous leprosy. There were heavy nodules and diffuse infiltrative lesions seen over the entire body, being the heaviest on the face and 
ear lobes. The right eye showed a scleral nodule. There were rather advanced mucosal lesions and nasal septal ulceration. There was buccal and laryngeal mucosal infiltration.

Treatment with Streptovaricin was started in January, 1957. He had had no previous treatment. The drug was tolerated and at no time were any toxic manifestations noted. He did, however, show a number of mild ENL reactions. At the 11 th and 23rd months brief rest was given. At the 14th 21 st and 26th months the dose was reduced but treatment was not interrupted.

He has now completed 35 months of treatment. Total dose: 2104.4 grams.

Histopathological Reports on biopsy material sent for examination:

1.st Biopsy (18/1/57), 510 (Lab. No. 2494)

H. E. Section: There is a massive and gross infiltration throughout the corium leaving a narrow, free sub-epidermal zone. The infiltrate occupies the whole of the dermis and is very dense. The infiltrating cells are round cells and macrophages. Many of the macrophages have the appearance of epithelioid cells. Here and there, there seems to be some foamy cell degeneration. The nerves are so involved in the granulomatous tissue that only an occasional one is recognised, but in these nerve tissue is recognisable. The infiltrate presses up around the nerve and one would consider that when there is organisation of this infiltrate there will be considerable fibrosis. The skin appendages are also involved in the gross infiltrate and these are reduced in number.

F. F. STAIN: Very large numbers of acid-fast bacilli seen throughout this section with numerous globi. The acid-fast bacilli show little morphological change. Nerves are recognisable, and there appears to be a considerable increase in Schwann cells. Most of the macrophages show large numbers of bacilli within the cells.

DiAGNOSIS: Advanced infiltrated lepromatous leprosy.

2nd Biopsy (26/1/57), 524 (Lab. No. 2565)

H. E. SECIION: A massive infiltration is seen throughout the corium leaving a narrow clear sub-epidermal zone extending deep into the corium. The granulomatous infiltrate shows marked foamy cell change with interspersed round cells, but plasma cells are not conspicuous. Granulomatous infiltrate is so massive that all the skin elements are obliterated and nerves are not recognisable.

F. F. StaIN: Acid-fast bacilli in very large numbers seen throughout the section and in rod forms and clusters. There are no characteristic globi seen. DiaGNosis: Active, advanced lepromatous case, not in reaction. I do not think that the fact that nerves are not seen is necessarily significant, because they are probably unrecognisable among the gross foamy cell change.

3rd Biopsy (19/2/58), 556 (Lab. No. 3015)

H. E. Section: Diffuse infiltration underneath the epidermis of moderate intensity, leaving a relatively clear sub-epidermal zone. The infiltrate is scattered diffusely throughout the corium of the skin with some relationship to the skin appendates, but with no evidence of any focalisation. The infiltration consists very largely of histiocytes. On one area there is quite definite foamy cell change, and in another area in the vicinity of a hair follicle and near to the epidermis there is a small collection of round cells. Nevres, when seen, are quite uninvolved.

F. F. Staln: Very numerous acid-fast bacilli seen throughout the section which are undergoing considerable morphological change.

DiAGNosis: Moderate lepromatous leprosy, showing considerable influence of sulphone therapy. It is possibly a lesion which is responding to therapy fairly well.

4th Biopsy (22/1/59), 569 (Lab. No. 3354)

H. E. Section: There is a moderate infiltration underneath the epidermis and throughout the corium with a clear sub-epidermal zone. Immediately under the epidermis the infiltrate is seen as a continuous band. In the deeper layers of the corium the infiltrate, generally speaking, is around the appendages of the skin, but there is no evidence of focalisation. The infiltrate consists almost entirely of histiocytes (macrophages) practically all of which have undergone foamy cell change. In addition there is interspersed between the foamy cells considerable round celled infiltration and a definite increase in plasma cells. Nerves are not easily recognised.

F. F. Stain: Several nerves were seen; they were seen to be uninvaded and 
show increase in Schwann cells. Very numerous acid-fast bacilli seen throughout the section showing little or no morphological change.

DIAcinosis: A very active, moderately advanced lepromatous case.

5th Biopsy (20/11/59), 579 (Lab. No. 3744)

H. E. Section: Practically all the corium is occupied by a mass of infiltration consisting almost entirely of foamy cells. Interspersed between the foamy cells are round cells and an occasional plasma cell. The infiltrate does not go up to the epidermis and leaves a very clear and well defined free subepidermal zone. The infiltrate is so gross that nerves are quite unrecognisable among the mass of foamy cells.

F. F. STAIN: Acid-fast bacilli seen in scanty numbers in most microscopic fields. In addition, I think I can make out some nerve tissue and there does not seem to be any. evidence of nerves being involved in the infiltrating process.

Diagnosis: This is a moderately early, somewhat active lepromatous case.

\section{Conclusion}

We note at this time that there has been very marked clinical improvement as seen in the resolution of the nodules and diffuse infiltrative lesions. There remains, however, widespread moderately heavy nodular and diffuse infiltrative lesions. The feet and hands show brawny oedema.

The nasal septal mucosal ulceration persists. The scleral nodule is resolving. The other mucosal lesions are showing resolution.

The bacteriological index went from a high of 5.2 early in the study to 2.6 at the present.

There would appear to be very significant clinical and bacteriological response to treatment, but we feel that the response is comparable to that which we could have expected on sulphones. The histological reports on this case show quite definite improvement. The last biopsy shows a decrease in the number of bacilli in the section and the 3rd biopsy shows that these bacilli are undergoing gross morphological change, but whether this improvement will be maintained is difficult to say.

\section{Summary and Conclusions}

In our experience we have found Streptovaricin to be a well tolerated non-toxic drug. The only complaint we heard from the patients was that 15 capsules at one time was a little difficult to take.

We note that in all cases there were mild Erythema Nodosum Leprosum reactions which we feel is an indication of some effectiveness of the drug in dealing with the $M$. leprae. It should be noted that in all cases there was definite and significant clinical and bacteriological improvement.

One aspect of the study was the discouraging failure of the nasal mucosal lesions to respond to treatment. Similar lesions in patients treated with sulphones and Streptohydrazid would have shown rapid healing. ${ }^{13}$

Results of the biopsy examinations were not commensurate with the clinical improvement, and, on the whole, the biopsy results were disappointing. 
Therefore, we have to conclude that there is little evidence that Streptovaricin has any appreciable effect on the $M$. leprae as administered.

This series of cases is, admittedly, small; but in view of the fact that Streptovaricin alone has little or no effect on the M. leprae we would be prepared to undertake a trial of Streptovaricin used in connection with one of the sulphones. The expense of its manufacture, the necessity of high daily dosage, the lack of any superiority to existing drugs makes it questionable whether it is worthwhile to continue a further trial of Streptovaricin along with sulphones. These preliminary trials do not fulfill conditions which would justify further expense in experimental usage of these drugs.

\section{Acknowledgments}

We wish to express our thanks to the Upjohn Co. for the supply of the Streptovaricin used in this study and for their close cooperation in keeping us abreast with current findings in other fields of research.

\section{Bibliography}

1. Siminoff, P.; Robert, M.; Sakolske, W. T.; Savage, G. M. Am. Rev. Tuh. and Pul. Diseases, Vol. 75 (April, 1957), 576-583.

2. Whitfield, G. B.; Olson, E. C.; Ross, R.; Fox, J. A.; Bergy, M. E.; BOYACK, G. A. ibid. 584-587.

3. Rhuland, L. E.; Stern, K. F.; Reames, H. R. ibid. 588-593.

4. MCCune, R. M., et al. ibid. 659-666.

5. Karlson, A. G. Mayo Clinic, Proc. of Staff Meetings (April, 1958).

6. Chang, Y. T. Am. Rev. Tub. and Pul. Diseases, Vol. 79 (May, 1959), 673-676.

7. Wallaci, D. P.; Wagner, J. G. J. Pharmacol. Exptl. Therap., Vol. 124 (Sept. 1958), 16-24.

8. Nathan, A. Am. Rev. Respiratory Diseases, Vol. 80 (Sept. 1959), 424-425.

9. Des Prez, et al. ibid. 431-433.

10. U.S.P.H.S. Tuberculosis Therapy Trials. ibid. 757-759.

11. Riley, E. A.; Simpson, D. G.; Bowen, J. F. ibid. 426-430.

12. Cochrane, R. G. Leprosy in Theory and Practice (1959). Appendix III, 371.

13. Dreishach, J. A.; Cochrane, R. G. Lep. Rev. (July 1958), 29, 136-142. 